\title{
Graduate Learners' Perspectives of Developing 'Speaking' Skill in the Classrooms of Non-native English Speakers
}

\author{
Mohammad Ehsanul Islam Khan \\ Academician \& Researcher; Managing Editor, Journal of ELT and Education, Bangladesh
}

Hasnahana

MA Student, Macquarie University, Sydney, Australia

\begin{abstract}
The major focus of the current study is to know different students' perspectives on the different activities, which improve the learners' speaking skill in the English as Second Language (ESL) or English as Foreign Language (EFL) classrooms that are from different countries and background. The current research paper depicts the innovative activities that help learners' speaking skill and how these activities can be effective to graduate learners. The obstacles or benefits of those activities are also subjected to be surveyed. This is a qualitative and descriptive study in nature. The researchers selected 15 participants from 12 different countries where there were 3 male and 12 female participants. The data was collected through direct interviews and a focus group discussion (FGD) with open-ended questions. The research is based on the students' viewpoints of their previous experiences about the activities to improve speaking skill in the ESL/EFL classrooms. Therefore, the manuscript, in fact, deals with different classroom activities to improve speaking skill from the lens of graduate students. As all the students were professionals and were involved in the teaching profession, the researchers tried to depict their past experiences as a student and a teacher as well. Since they are still the students of language background, they could successfully opine for the best activities effective in their respective context of second or foreign language. The findings implicated using activities like- role play, debate, picture description, group activities, drama, competition, presentations, multicultural interactions, answering questions, songs, read aloud task, pair work that are effective as these activities can encourage and motivate by engaging the learners to learn a second or foreign language. Few participants also mentioned the obstacles like lack of confidence, shyness, and communication problem because of different cultural background and opinions and some talked about the benefits.
\end{abstract}

Keywords: classroom activities, graduate students, speaking skill.

JEL Classification: A23, J24.

Cite as: Khan, M.E.I., Hasnahana (2019). Graduate Learners' Perspectives of Developing 'Speaking' Skill in the Classrooms of Non-native English Speakers. Business Ethics and Leadership, 3(2), 107-112. http://doi.org/10.21272/bel.3(2).107-112.2019.

(C) The Authors, 2019. This article is published with open access at Sumy State University.

\section{Introduction}

Speaking in a second language beside the native one is an extraordinary quality (Mahbub-ul-Alam \& Khan, 2014). Speaking necessitates that learners not only know how to fabricate specific points of language such as grammar, pronunciation, or vocabulary (linguistic aptitude), but also that they understand when, why, and in what ways to produce language (sociolinguistic aptitude) (Burns \& Joyce, 1997). Mahbub-ul-Alam \& Khan (2014) also agreed with the viewpoints of Burns and Joyce in this regard. Nowadays speaking English has become necessary for getting a good career. It has been recognized as the foremost eligibility to find a better job. The entire world is getting closer and the people need an interactive language to communicate among one another. Accordingly, English has been playing the role of that language of communication since last few decades. English is playing that imperative role in the way of people's life being considered as an international language worldwide. From the influence of communication and information technology, English becomes as important as it is the main aspects of communication, seeking knowledge from different sources, which includes the career too (Wonglekha, 2010). More than that, the learners will find it easy to interact and communicate with people when they travel around the world (Gard \& Gautam, 2015). In several Asian and some other countries, English has been taught as a second or foreign language where learners' behavior in the classroom situation does not work properly as they are scared of making mistakes and feeling shy in front of the class. In addition to that, they also might respond with the short phrase as they may have a lack of confident 
ISSN (online) - 2520-6311; ISSN (print) - 2520-6761

and shy to speak. The graduate learners may titter too when they are sore and incapable to realize the lesson. So, the English teacher should create a rich environment to provide a meaningful communication among the learners with different speaking activities which make them more interested and active as well as making their learning more enjoyable and meaningful.

However, learners also should know the features of the language and have the ability to process them in communication. If any speaker can dominate these language features, it will help learners to acquire successful communication goal (Harmer, 2001).

This study is about the graduate students' perspectives to improve speaking skills with different activities. This is so significant for the learners' English speaking improvement that it tends to depict the effectiveness and impacts of different classroom activities from the viewpoints of some non-native English speakers. The study claims that the teachers, as well as the students, would be able to know the activities and benefits of those activities to develop the speaking skills from different perspectives.

\section{Objectives}

The major objective of the current study is to study the outcomes of different classroom activities to improve students' speaking skills in the ESL/EFL context of non-native English speakers. Therefore, the researchers intend to investigate students' lookouts towards the use of different speaking activities investigating the obstacles the learners' face during the activities.

\section{Literature Review}

When looking at a speaking activity, or any activity for that matter, it is highly advisable to have clear objectives in mind (Maximchuk, M. N., 2018). So, the current study aims at some specific activities and their outcomes in the class used by the non-native speakers. Having clear objectives in a task enhances the commitment of the participants as subconsciously defined goals may lead to lower dedication and presentation (Locke, 1996; Dornyei \& Ushioda, 2013). Therefore, some successful speaking activities with their effectiveness in the ESL/EFL speaking class to improve speaking, and the related problems during applying those activities are the focal points of this study. Role play is a very effective way for the students to speak (Kayi, 2006). In such activity, the students act like they are in different contexts with different roles. Students find it interesting as they can feel different social aspects. So, the researchers of the study dealt with a few aspects of role-plays while talking to the graduate participants. Besides, different types of games like cooperative, competitive, communication and code-control games (Klaueur, 1998) are also recognized as effective for the students' speaking skill. There might be more games such as pictures game, psychology games, magic tricks, story games, word games, questions- answers games, true-false games to make the speaking class interesting as well as to engage the students effectively (Wright et al., 1997). So, the study also discussed the impacts and related issues of such games to learn the basic four skills of English. Furthermore, dramatic activities provide a chance for the learners to utilize their personal integrities in their speaking skills (Maley \& Duff, 2011). The researchers believe that if the educators successfully deploy them, they will aid in reinforcing and improving communicative skills through those activities. The information gap is also a good strategy because it provides the scope to practice the learning materials by interaction, which is also easy to share information with the learners (Harris, 1990). It is such a learning activity where the foremost responsibility of a learner is to work with pair or group where the task will be incomplete if the learners do not have the active communication in English (Kayi, 2006). Accordingly, the study sought for the impactful aspects of working in groups from graduate learners' eye.

Many researchers consider 'Group Discussion' as an effective activity to improve learners' speaking as the learners may also have different opinions, solutions or conclusions but here motivation is important for the students to ask and answer questions, summarize and clarify the ideas and also to give support (Kayi, 2006). Furthermore, the debate is another effective activity, which develops the argumentation skills and also engages the learners in a successful speaking with the listening and writing practice.

However, the study in fact sought for the outcomes of using those activities in the classrooms of non-native speakers, not the system or approach of applying it. For that, the researchers considered a few aspects of utilitarianism in using such activities in the class. So, they tried to know about the scopes and the approaches to the best use of these activities as per the suggestions of different experts. Ur (1999) states that in any good activity there should be plenty of time for the learners to speak where all the participants will participate in the task equally. He (Ur, 1999) further states that motivation must play a vital role to encourage the learners to speak eagerly with the acceptable level of language accuracy in this regard. The participants of this study were 
Business Ethics and Leadership, Volume 3, Issue 2, 2019 ISSN (online) - 2520-6311; ISSN (print) - 2520-6761

asked if they got adequate time for the best output of the activities as different activities can expand the confidence. Games are also welcoming as they are different from the regular routine and also challenging as well as motivating with the diverse skills practice - speaking, listening, reading and writing where there is a meaningful use of language (Lee Su Kim, 1995). These activities can connect between the classroom circumstances with the practical condition.

Again these effective activities may also have some tribulations that the learners face while completing the tasks like: the learners may feel shy to speak as the other learners are listening or become nervous about making mistakes and sometimes the learners do not have anything to say; there may be some dominating participants who control the task and other may have less chance to speak; there is another common problem of using native language instead of using the target language in the class (Ur, 1996). The researchers considered the "interactional effects and affective factors" (Brown, 2001) that are the primary reasons for the speaking difficulties.

Cultural, linguistics, effective or psychological factors also arise the speaking difficulties (Burns and Joyce, 1997). Therefore, the study also sought for the quandaries during the use of those activities from the graduate participants. Only to have the knowledge of the language is not enough for EFL learners to speak effectively and appropriately. They should be familiar with the culture of the native speakers to be able to use target language, which is socially and culturally acceptable by native users (Richards \& Renandya, 2002). Thus, the study looked for the ways of adopting the social or cultural approaches through the sample classroom activities to be adept in spoken English and to adapt to the current English learning situation all over the world.

\section{Methodology}

In this study, qualitative research method was used as a method as the researchers were intended to investigate the opinion of using activities in the ESL/EFL classes to improve learners speaking skills and the participants shared their opinions. This study examined 15 graduate learners doing MA in Applied Linguistics and TESOL at Macquarie University, Sydney, Australia; MA in English at Manarat International University, Dhaka, Bangladesh and MA in ELT at Jahangirnagar University, Dhaka Bangladesh to identify the types of activities, which develop both of their students' speaking proficiency along with the effectiveness of those activities. There were 15 participants in this study where there were three male and 12 female graduate students. The participants were from 12 different countries from Bangladesh, China, Greece, India, Indonesia, Japan, Korea, Malaysia, Myanmar, Nepal, Sri Lanka, and Vietnam. The foremost reason for selecting the participants from these countries is that they all are non-native English speakers. Therefore, the researchers collected data from these participants to know their standpoints of the impacts and the fruitfulness of those activities undertaken by their tutors or instructors. All participants speak English as a second or foreign language, and English is not their native tongue. The participants were from a different background, culture and different learning experiences who shared their own experiences and opinions. The study was a descriptive study in nature. The utmost supportive methods for the study were direct interviews and two focus group discussion.

The first focus group discussion (FGD) held in Australia with the non-native English speakers conducted by the second author having seven participants with reference to their discussions on the open-ended questions in the relevant topic. Three participants answered the questions through direct interviews. Five participants attended a focus group discussion in Bangladesh headed by the first author. The participants were also interviewed directly, for which the duration of each interview was 5 minutes. Then the results of the two FGDs were analyzed and combined to get the learners' opinions towards the classroom activities to develop their speaking skills and those questions were developed by the researchers by studying different literature related to this research and also discussing with experts on this area. The FGD covered three segments: the first one was about the types of activities that are supportive to develop non-native English learners' speaking ability; the second one was about the effectiveness of those activities, and the third one was about their experiences like whether they experienced any obstacle during those activities or not and what those were; and if they did not face any problem then they shared the benefits of those class activities. The data was collected primarily from the FGD and interview session. The secondary data was collected from the reviews of the related articles on improving speaking with different classroom activities.

\section{Findings and Discussion}

The paper tends to reveal the previous approaches concerning the current traditions of using different activities in the language classroom of the non-native speakers to improve the English speaking skill. 


\subsection{Activities used by the teachers of a non-native speaker}

Based on the open-ended questions in the FGD from the participants, it has been found that the activities likegroup or pair discussion, debating, role-plays, storytelling, picture description, oral presentations, questionanswer sessions after lesson, drama, games, read aloud tasks were used by the teachers in their ESL/EFL classrooms. Though the participants were from different culture and background, they mentioned the similar types of effective activities to improve English speaking skills. Just the difference was the way of delivering and the frequency of usage in the classrooms.

In the first segment, all the $15(100 \%)$ participants talked about the role-plays, group discussions and presentations considering these as the preconditions of being an adroit speaker. Again, 13 (86.67\%) participants opined for debate and picture description to nurture the stock of using vocabularies. $10(66.67 \%)$ participants mentioned the effectiveness of question-answer activity for improving speaking. Eight (53\%) graduates mentioned about singing songs, competition, and drama; three (20\%) pointed out multicultural interactions, two (13.33\%) stated read-aloud task. Another one (6.67\%) mentioned about the online games for speaking and grammar. They admitted that these activities were effective activities for their language classrooms to develop the students' speaking skill from their real-life experiences.

\subsection{Efficacy of the activities}

The second segment was about whether those activities were effective or not. All the participants (100\%) were agreed to this point and they mentioned how and why they are effective. They said these activities were as effective as they motivated and engaged the learners. Students can have much time to speak; they allow the ESL/EFL learners to learn spoken language through the interactions with others; these activities help learners to involve into the real-life contexts with the communication skills improvement.

\subsection{Quandaries during the activities}

The third segment was about whether they experienced any quandaries during those activities or not. From the 15 participants, six (40\%) participants opined that they did not face any obstacles or problem during those activities but they felt more confident but another nine $(60 \%)$ participants opined that the activities were so beneficial and effective for them but they faced some troubles too. The problems they mentioned were hard to communicate with partners or group mates due to the different cultural background and opinions; lack of motivation and confidence; due to large class size there was not enough time to assist every student; if the students are from the same ethnic group, they start talking in their mother tongue. Some students felt shy or scared to participate in the activity; on the other hand, some students were not willing to participate in the task when some were more enthused to participate so it created problems.

\subsection{Learners' Positivism}

Though the participants talked about some problems, they had a positive attitude towards applying the activities in the ESL/EFL classrooms for the development of learners' speaking skill. The participants had different opinions but they had a general agreement in some activities such as role-play, group discussions and presentation were mentioned by all. All the above mentioned activities are learners-centered classroom activities. These learner-centered classroom activities even encourage the shy students to speak with face to face communication, to work independently and even they have the minimal involvement to improve their speaking skills. Few graduates opined that there is no activity effective enough like the face to face communication among people of a group. There are some effective activities like: pair/group work, interview and role playing, which encourage and motivate the shy learners to participate and share their opinions with their group members rather than with teachers.

In the final segment, the researchers investigated the personal quandary faced usually by the graduates if there is any to speak English as a foreign or second language. As per the supposition, ESL learners opined not to have any bar to speak English. Contrarily, EFL graduates depicted a few obstacles in English. 10 (66.67\%) learners considered 'mother tongue interference' is a fact to speak English in a fluent manner though the rest of the participants (five) did not support the fact. Mother tongue interference is found in both of the EFL and ESL contexts. Native speakers of English can easily recognize whether someone is French or Arab after a few words of English (Ridha, 2012). The use of mother tongue during speaking English is not similar in these two contexts. Usually, graduates of ESL context were not at all agreed to consider it as a flaw of interaction especially, while talking to any native English speaker. According to Olana, Zeleke \& Jiregna (2015), learning English as a foreign language is not an easy process because of the ransfer of learners' native language to a 
second language. A student must need time to master a language organizing their understanding into the logical formation. The current study also agreed to the similar viewpoint of Olana et al. (2015).

\section{Recommendation}

The researchers would like to suggest some points after concluding the result of the research - it is so important that the teacher should create an enjoyable situation to motivate the learners to improve their English speaking. So the teacher can use different activities in the classroom and also the teachers have to be careful and follow some techniques or strategies to engage the learners equally and make them feel comfortable. Besides, the students also should encourage themselves to learn more to develop themselves. It is recommended that the researchers conduct further research to investigate the strategies or solutions to decrease the obstacles or problems, which are faced, by the learners and teachers during the activities.

Making mistakes and errors when learning a new language is something inevitable. However, teachers should not discourage students by correcting every single error. It is also needed that teachers highlight common errors learners of a target language make in their learning process. So, if any student uses mother tongue interference during speaking, the teacher should correct them in a positive approach not considering the mistake as a gross one (Thyab, 2016).

While preparing learning materials, real-life communication should be facilitated and learners' background knowledge should be kept in mind, and their known context to be chosen so that the learning process becomes an interesting journey. In EFL Speaking class, 20:1 student-teacher ratio should be ensured for the effective outcome and class duration should be increased from 45 minutes to two hours in order to utilize sufficient time for every student regarding pair/group practice, individual presentation and problem-solving session (Yousuf, 2018).

There are many learners who are interested to learn through games. In that case, the teacher must give them the adequate directions to use games and give feedback after playing as Kleur (1998) mentions that for a game activity there must have some rules with the beginning and ending points for reaching to the aim, which also has the objectives to make the task easy.

\section{Conclusion}

This study revealed that using different activities in the ESL/EFL classrooms develop learners' speaking skills. Apart from some problems, it is clear that learners get more enjoyment, confidence, interest, and motivation in their learning through those activities. Therefore, different communicative activities should be applied in teaching speaking skills as designed activities. The teaching exposes the students with the activities to the situations where they express their feelings, ideas, and thoughts. As the participants were from different backgrounds and cultures, this was so effective to find out the productive data to investigate.

It is recommended that the activities should be included in the lesson plan in the ESL/EFL classrooms. Teachers should provide numerous opportunities to the students with intercultural exploration when they encounter new cultural aspects on their culture and it is possible to create their interests as peoples' feeling and activities are linked with language which is also bound with religion, culture, social status, profession and nationality and by learning from others on how to convey, one can express their feeling properly.

\section{References}

1. Burns, A. \& Joyce, H. (1997). Focus on Speaking. Sydney: National Centre for English Language Teaching and Research.

2. Derakhshan, A., Khalili, A. N. \& Beheshti, F. (2016). Developing EFL Learner's Speaking Ability. English Language and Literature Studies, 6(2), 177-186.

3. Dörnyei, Z. \& Ushioda, E. (2013). Teaching and Researching Motivation (Second Ed.), Applied Linguistics in Action Series, Routledge: New York.

4. Garg, S., and Gautam, A. (2015). Learning English can change your life for the better. International Journal of English Language, Literature and Humanities, 3(2), 560-568.

5. Harmer, J. (2001). The practice of English language teaching (3rd ed). London: Longman.

6. Harris, K. A. (1990). Pair Activities in Beginning Adult ESL Classes. Retrieved 10 December 2018 from http://www.calproonline.org/files/i_presenterpowerpointsandhandouts/i_pdfs_presenterpowerpoints/302_harris_pairwork.pdf.

7. Klaeur, C. (1998). Using Games in Language Teaching. Retrieved 25 December 2018 from http://maxpages.com/maxpagesplus. 
Business Ethics and Leadership, Volume 3, Issue 2, 2019

ISSN (online) - 2520-6311; ISSN (print) - 2520-6761

8. Kayi, H. (2006). Teaching Speaking: Activities to Promote Speaking in a Second Language. The Internet TESL Journal, 12(11), 01-08.

9. Kim, L. S. (1995). Creative Games for the Language Class. Forum, 33(1), 35.

10.Locke, E. A. (1996) Motivation through conscious goal setting. ELSEVIER: Applied and Preventive Psychology, 5(2), 117-124. Available at: https://doi.org/10.1016/S0962-1849(96)80005-9.

11.Mahbub-ul-Alam, A. \& Khan, M. E. I. (2014). Speaking in a Second Language in Bangladesh. NU Journal of Humanities, Social Sciences and Business Studies, 1(1), 135-142.

12.Maley, A., \& Duff, A. (2011). Drama techniques: A resource book of communication activities for language teachers (3rd Edition). In P. Ur (Series Ed.), Cambridge Handbooks for Language Teachers, Cambridge: CUP.

13.Maximchuk, M. N. (2018). Today's Theme: The Creation of an Activity to Enhance Speaking in the Classroom. Journal of ELT and Education, 1(1), 29-33.

14.Nunan, D. (1991). Language Teaching Methodology: A Textbook for Teachers, Hertfordshire, Prentice Hall, 39-62.

15.Olana, T., Zeleke, T. \& Jiregma, K. (2015). Mother tongue interference in English Language Writing at Derge Secondary School: The Case of Grade 9 Students. Science, Technology and Arts Research Journal, 4(4), 208-214.

16.Richards, J. C., \& Renandya, W. A. (2002). Methodology in language teaching, New York: Cambridge University Press. Available at: http://dx.doi.org/10.1017/CBO9780511667190.

17.Ridha, N. (2012). The effect of EFL learners' mother tongue on their writings in English: An error analysis study. Iraqi Journal of the College of Arts (University of Basrah) 60, 22-45.

18.Thyab, R. A. (2016). Mother-Tongue Interference in the Acquisition of English Articles by L1 Arabic Students. Journal of Education and Practice, 7(3), 01-04.

19.Ur, P. (1996). A course in language teaching, Cambridge: Cambridge University Press.

20.Wonglekha, F. (2010). English Development for Thai Children to ASEAN and Global Arena. Retrieved 15 July 2018 from http://social.obec.go.th/node/89.

21.Wright, A., Betteridge, D., and Buckby, M. (1997). Games for Language Learning, Cambridge: Cambridge University Press.

22.Yousuf, M. A. (2018). Teaching Efl Speaking at the Tertiary Level: A Study in Bangladesh Context. Journal of ELT and Education, 1(1), 91-100. 